of the exposure. This appears to me to mean that at any particular temperature there may be no absolute rate for a biological process, and that all conditions previously experienced by the animal must be considered. Otherwise any theory based on the speed of a reaction must be treated with great caution.

Kenneth Mellanby.

The University,

Sheffield, 10.

July 10.

${ }^{1}$ Crozier, W. J., J. Gen. Physiol., 7, 189 (1924).

Mellanby, K., Proc. Roy. Soc., B, 127, 473 (1939).

${ }^{3}$ Mellanby, K., J. Physiol. (in press) (1940).

\section{Evidence of Demethylation in the Animal Body}

DURING the course of work on the metabolism of synthetic ostrogenic compounds ${ }^{1}$ undertaken at this Institute, attention has been directed to the methyl ethers of some of the synthetic œestrogenic phenols. Preliminary experiments have been carried out on 4: $4^{\prime}$-dimethoxy diphenylether and 4-methoxy diphenyl ; $4: 4^{\prime}$-dihydroxy diphenylether having been shown to produce full œstrous response when injected at a dose of $100 \mathrm{mgm}$. into ovariectomized rats, and 4-hydroxy diphenyl shown to have no œstrogenic activity at a dose of $100 \mathrm{mgm} .^{2}$

$3 \mathrm{gm}$. of $4: 4^{\prime}$-dimethoxy diphenylether, dissolved in sesame oil, were injected into two female rabbits over a period of three weeks, the urine being collected during this period and for a further week after the last injection. From the 'free' and 'combined' phenolic extracts prepared from the urine a crystalline phenol was obtained by repeated extraction with boiling water, $47 \mathrm{mgm}$. occurring in the 'free' state and $22 \mathrm{mgm}$. in the 'combined' state. After several recrystallizations from petroleum ether this phenol melted at $90^{\circ} \mathrm{C}$. and was shown to be 4-methoxy$4^{\prime}$-hydroxy diphenylether.

$3 \mathrm{gm}$. of 4-methoxy diphenyl were injected into two rabbits in the same way as above, and a crystalline solid obtained from the 'free' and 'combined' phenolic extracts prepared from the urine, $203 \mathrm{mgm}$. occurring in the 'free' state and $43 \mathrm{mgm}$. in the 'combined' state. After several recrystallizations from benzene $30 \mathrm{mgm}$. of a crystalline phenol m.p. $268^{\circ} \mathrm{C}$. were obtained and shown to be identical with $4: 4^{\prime}$.dihydroxy diphenyl m.p. $272^{\circ} \mathrm{C}$. From the benzene mother liquors $111 \mathrm{mgm}$. of another crystalline phenol m.p. $162^{\circ} \mathrm{C}$. were obtained and shown to be identical with 4 hydroxy diphenyl, m.p. $163^{\circ} \mathrm{C}$.

These results show that demethylation definitely occurs in the animal body and gives support to the suggestion made by Westerfeld ${ }^{3}$ that œestrone methyl ether is metabolized in the body to œstrone.

Work on the metabolism of the methyl ethers of the highly active synthetic ostrogenic phenols is now in progress.

$$
\text { S. W. Stroud. }
$$

Courtauld Institute of Biochemistry,

Middlesex Hospital Medical School, London, W.1. July 3.

${ }^{1}$ Stroud, S. W., J. Endocrin., 1, No. 2, 201 (1939) ; 2, No. 1, 55 (1940). ${ }^{2}$ Dodds, E. C., and Lawson, W., Proc. Roy. Soc., B, 125, 222 (1938), ${ }^{3}$ Westerfeld, W. W., Biochem. J., 34, 51 (1940).

\section{Resonance in the Chloroacetic Acids}

IN a recent letter ${ }^{1}, H$. O. Jenkins has made the interesting suggestion that the high acid dissociation constants of di- and tri-chloroacetic acids are largely due to the possibility of a resonance structure in their anions. It is the purpose of this note to indicate a possible means of testing this hypothesis.

The strengths of acids or bases are in general a good measure of the velocity with which they will lose or gain protons. This is shown by the wide validity of relations of the form $k=G K^{\alpha}$, where $k$ is the velocity of a catalysed reaction, $K$ the strength of the catalysing acid or base, and $G$ and $\alpha$ eonstams for a given solvent, temperature and reaction ${ }^{2}$. However, this parallelism will break down if the acid and base involved in the equilibria used for defining acid-base strengths have different electronic structures. The extreme case of this behaviour is met with in pseudo-acids, where the charge on the anion may reside on an atom other than that from which the proton has been removed (for example, $\left.\mathrm{CH}_{3} \mathrm{NO}_{2} \rightarrow \mathrm{CH}_{2}: \mathrm{NOO}^{-}+\mathrm{H}^{+}\right)$. This point was realized by Brönsted when he first proposed quantitative relations of the above type, and it was in fact shown that in the decomposition of nitramide the jons of pseudo-acids had a much smaller catalytic effect than would be predicted from their dissociation constants ${ }^{3}$.

The same type of argument applies in general to cases where resonance structures occur in only one member of an acid-base pair. In the case of dichloroacetic acid, let the 'normal' molecule and ion be denoted by $\mathrm{H} A$ and $A^{-}$, and the resonance structures $\stackrel{\mathrm{Cl}}{\mathrm{Cl}_{\mathrm{C}}} \stackrel{+}{\mathrm{C}} \mathrm{COOH}$ and $\stackrel{\mathrm{Cl}}{\mathrm{Cl}} \stackrel{+}{\mathrm{C}} \mathrm{H} . \mathrm{COO}^{-}$by $\mathrm{H} R$ and $R-$ Let us suppose for the sake of simplicity that the molecule exists almost entirely as $\mathrm{H} A$, and the ion almost entirely as $R^{-}$. The best measure of the tendency of $\mathrm{H} A$ to lose a proton is given by the constant $[\mathrm{H}+]\left[A^{-}\right] /[\mathrm{H} A]$, which is much smaller than the observed dissociation constant $[\mathrm{H}+]\left[\mathrm{R}^{-}\right] /$ $[H A]$ : hence the dichloroacetic acid molecule will be a less powerful acid catalyst than would be expected from its dissociation constant. Similarly, the tendency of $R^{-}$to pick up a proton is represented by $[\mathrm{H} R] /[\mathrm{H}+]\left[R^{-}\right]$, which is smaller than the observed constant $[\mathrm{H} . A] /\left[\mathrm{H}^{+}\right]\left[\mathrm{R}^{-}\right]$: hence the dichloroacetate ion will be a less powerful basic catalyst than would be expected from the dissociation constant of the acid. In a catalytic reaction involving dichloroacetic acid or its ion, the transition state will actually be intermediate in structure between $A$ and $R$, but the same qualitative conclusions will apply.

There is a certain amount of experimental evidence for the existence of this effect. Thus in the iodination of acetone ${ }^{4}$, the catalytic effect of dichloroacetic acid is about 30 per cent lower than the value calculated from an equation based on seven other carboxylic acids (average deviation 8 per cent). Similarly, in the docomposition of nitramide ${ }^{3,5,6}$, the catalytic effect of the dichloroacetate ion is $\mathbf{3 5}$ per cent lower than the calculated value (based on twelve other anions : average deviation 4 per cent). There appear to be no other cases for which sufficiently full or accurate data are available.

These results lend some support to the view that a resonance structure plays a part in the dichloroacetate ion. On the other hand, the effects observed 